\title{
A segurança e saúde no trabalho no regime CLT e no regime estatutário: uma abordagem no planejamento governamental comparando o tema nos dois regimes
}

\section{RESUMO}

Junior Cesar de Almeida juniorlds@hotmail.com Univerisdade Tecnológica Federal do Paraná, Curitiba, Paraná, Brasil

Isaura Alberton de Lima alberton@utfpr.br Paraná, Curitiba, Paraná, Brasil

\begin{abstract}
A segurança e saúde no trabalho SST é tema de grande relevância, sobretudo, em razão do elevado custo financeiro, social e para a saúde dos trabalhadores relacionados aos agravos decorrentes dos riscos existentes nas atividades laborais. Desde a Revolução Industrial e no Brasil desde o fim da escravidão o tema vem progressivamente adquirindo maior importância e chamando a atenção das autoridades públicas. No Brasil a SST é amplamente abordada e disciplinada na legislação trabalhista através das disposições da Consolidação das Leis Trabalhistas - CLT e das Normas Regulamentadoras, emitidas pelo Ministério do Trabalho, além de outros instrumentos legais afins. Entretanto, no âmbito do serviço público a realidade é bastante diferente. Apesar de o setor público abrigar diversas atividades que implicam em riscos à saúde e à integridade física de seus trabalhadores, a SST é marcada pela omissão legislativa nesse setor. Enquanto no regime CLT a disciplina legal e regulamentar do tema é bastante abrangente, no serviço público, a disciplina do tema resume-se a tratar dos adicionais ocupacionais, deixando de lado importantes programas e medidas utilizadas no regime celetista. $\mathrm{O}$ objetivo deste estudo é propor alternativas para sanar a omissão legislativa e regulamentar sobre SST no regime jurídico único federal (estatutário).
\end{abstract}

PALAVRAS-CHAVE: Segurança. Saúde. Trabalho. CLT. Público. 


\section{INTRODUÇÃO}

Entre as atividades exercidas por uma pessoa durante sua vida, o trabalho ocupa posição de destaque consumindo grande parte, e em muitos casos a maior parte, do seu tempo de vida. Por essa razão, é muito comum a ocorrência de agravos à saúde e a integridade física do indivíduo por situações ligadas à sua atividade laboral.

Apesar de a relação do homem com o trabalho já notadamente datar de milênios, foi apenas a partir da Revolução Industrial que os problemas sociais e de saúde a ele ligados passaram a chamar a atenção de governantes e da sociedade. As mudanças ocorridas na dinâmica do trabalho tiveram como consequência o frequente adoecimento e morte de trabalhadores. $O$ crescente uso máquinas, a utilização da mão de obra de crianças, as jornadas de trabalho excessivamente longas e a grande concentração de operários em espaços pequenos e inadequados, com péssimas condições de higiene e salubridade foram fatores que contribuíram para esses agravos (SANTOS, 2011).

No Brasil as preocupações com esses agravos chegariam mais tarde, aproximadamente um século após o início da revolução industrial na Europa, sobretudo após a promulgação da lei áurea em 1888. O fim da escravidão representou o início do trabalho livre no país, e consequentemente um novo panorama social propício à introdução de normas disciplinadoras do trabalho. Apesar disso, foi apenas na era Vargas (a partir de 1930) que o tema do trabalho passou a integrar de forma significativa a pauta do governo. Nesse período houve uma intensa sistematização de normas que visavam disciplinar o tema, com destaque para a Consolidação das Leis Trabalhistas - CLT em 1943 (BRASIL, 1943). Muitas dessas normas continuam em vigor até os dias atuais (DELGADO, 2012).

No contexto das normas trabalhistas há destaque para Segurança e Saúde no Trabalho - SST, visto que seu objetivo é atenuar os principais agravos relacionados ao trabalho. No Brasil a SST que já havia sido objeto de previsões constitucionais e legais anteriores, foi amplamente regulamentado da década de 1970 com o advento da lei 6.570/74 que Alterou o Capítulo V do Titulo II da Consolidação das Leis do Trabalho, relativo à segurança e medicina do trabalho e abriu o caminho para a publicação das Normas Regulamentadoras - NR, normas essas que disciplinam o tema da SST amplamente. Essas normas atendem de maneira satisfatória a matéria da SST no âmbito das relações de trabalho regidas pela CLT (BRASIL, 1974).

Mas, ao lado do Regime celetista, há um grande contingente de trabalhadores que em razão de terem sua relação de trabalho disciplinada pelo regime estatutário podem não ser albergados pela mesma proteção destinada aos trabalhadores em geral (celetistas): trata-se dos servidores públicos.

Essas duas classes de trabalhadores estão submetidas a diferentes ramos do direito. Enquanto os trabalhadores celetistas estão amparados pelo direito do trabalho, os servidores públicos têm sua relação de trabalho maneada pelo direito administrativo.

Enquanto no regime CLT a disciplina legal e regulamentar do tema é bastante satisfatória em termos de abrangência, no serviço público, a realidade é bastante diferente. A disciplina do tema, nesse regime, resume-se a tratar dos adicionais ocupacionais, deixando de lado importantes programas e medidas que são 
utilizadas no regime celetista com grande êxito há décadas, a exemplo do Programa de Prevenção de Riscos Ambientais - PPRA, o Programa de Controle Médico e Saúde Ocupacional - PCMSO e a Comissão Interna de Prevenção de Acidente CIPA, entre outros.

O presente estudo tem como objetivo propor alternativas para superar a omissão legislativa e regulamentar sobre saúde e segurança no trabalho no regime jurídico único federal (estatutário), para garantir uma maior isonomia de tratamento entre os servidores públicos e os trabalhadores do regime celetista, no que diz respeito à proteção de sua saúde e segurança no trabalho. Busca-se identificar o tratamento dado ao tema da segurança e saúde no trabalho no regime celetista e no regime estatuário do serviço público federal. Busca-se também comparar os dois regimes no tocante ao tema de SST, busca-se ainda, identificar as principais diferenças existentes no trato normativo (leis e regulamentos) sobre saúde e segurança do trabalho de um regime em relação ao outro, ressaltando os problemas, incoerências e contradições que delas são emanados. Por busca-se propor alternativas de solução para os problemas encontrados.

O presente trabalho tem como base pesquisa bibliográfica e documental. Busca-se através de uma análise de obras acadêmicas e literárias especializadas e de documentos (leis, decretos-lei, decretos, medidas provisórias, textos constitucionais (das diversas constituições brasileiras), emendas constitucionais, normas regulamentadoras, orientações normativas, etc.) traçar um panorama conceitual e legislativo sobre o tema da segurança e saúde no trabalho tanto no regime celetista como no regime jurídico serviço público. Para tanto se debruça sobre a formação histórica e principais características de cada um dos dois regimes. Posteriormente faz-se uma análise comparada dos dois regimes identificando-se as principais diferenças entre os dois regimes no que tange a segurança e medicina do trabalho e identificando a existência de uma omissão legislativa sobre o tema no regime. Por fim, com base nessa comparação busca-se apontar alternativas para sanar essa omissão.

\section{JUSTIFICATIVA}

O tema da Segurança e Saúde no Trabalho tem chamado muito a atenção em razão dos alarmantes agravos sociais e econômicos relacionados a acidentes e doenças ocorridas no trabalho. Segundo a Organização Internacional do Trabalho (OIT) cerca 2,34 milhões de pessoas morrem por ano em acidentes de trabalho e doenças relacionados ao trabalho. Estima-se que cerca de $4 \%$ do Produto Interno Bruto (PIB) mundial, o equivalente a 2,8 trilhões de dólares, são desperdiçados por ano com custos diretos e indiretos em razão de a acidentes de trabalho e doenças relacionados ao trabalho (OIT, 2016).

Segundo Informações do Anuário Brasileiro de Proteção 2015, que se baseia em dados do Anuário Estatístico da Previdência Social, no ano de 2013, no Brasil, foram registrados 717.911 acidentes no total, 2.814 óbitos e 16.121 incapacidades permanentes. (REVISTA PROTEÇÃO, 2015). Focando sua análise no ano de 2009 Pastore (2011) defende que o custo total que a sociedade brasileira teve com acidentes e doenças relacionados ao trabalho pode ser calculado em cerca de R\$ 71 bilhões naquele ano. 
Diante desse panorama, e a despeito da necessidade de avanços no tema, é inegável que a incorporação de normas de Segurança e Saúde do Trabalho ao ordenamento jurídico brasileiro representa uma importante conquista para os trabalhadores. A legislação brasileira sobre SST baseia-se em critérios internacionais amplamente aceitos e confere aos trabalhadores importantes garantias no que tange a sua segurança, saúde e integridade física no trabalho.

Mas, a proteção existente ao trabalhador brasileiro destina-se notoriamente aos trabalhadores regidos pelo CLT, excluindo dessa forma os trabalhadores do serviço público, pois, estes se submetem ao regime estatutário e não ao regime CLT. A despeito da existência de vozes que defendem que aplicação da regulamentação trazida para os trabalhadores celetista deveria ser aplicada também aos servidores públicos, tal solução poderia implicar em violação de importantes pressupostos do direito administrativo, a exemplo do princípio da legalidade.

Diante disso, os servidores encontram-se desamparados ante os notórios agravos que decorrem da ausência de uma regulamentação no tema de SST.

O presente trabalho busca explorar o intricado problema apresentado expondo as principais questões relacionadas à regulamentação em SST na comparação entre os dois regimes de trabalho (RJU e CLT), para apresentar alternativas que possam equacionar a omissão regulamentar que atinge o serviço público.

\section{DISCUSSÃO}

A regulamentação da SST tem o importante papel de criar mecanismos que busquem promover as melhorias necessárias nos ambientes laborais para diminuir ou eliminar os riscos a que os trabalhadores estão expostos. Nesse aspecto, há grande prejuízo aos servidores públicos, já que seu regime prescinde de uma regulamentação sobre o tema.

\section{A aplicação das NR no Serviço Público}

A SST no âmbito do serviço público prescinde de uma regulamentação adequada. Os escassos dispositivos legais, ou regulamentares de tratam do tema limitam-se a disciplinar os adicionais ocupacionais.

Diante dessa omissão regulamentar o que se observa é uma tentativa de aplicação das Normas Regulamentadoras (NR) dos trabalhadores celetistas também ao Serviço Público. Entretanto, a utilização dessas normas sem a autorização legislativa expressa constituiria grave violação do princípio da legalidade a que a administração pública está submetida. Segundo esse princípio a administração pública somente pode fazer aquilo que lei previamente autoriza. Em outras palavras a administração publica nada pode fazer senão o que a lei determina. "Ao contrário dos particulares, os quais podem fazer tudo o que a lei não proíbe a Administração só pode fazer o que a lei antecipadamente autorize" (MELLO, 2010, p. 105)

Não havendo autorização, ao aplicar as normas regulamentadoras ao serviço público estaria a Administração Pública violando o princípio da legalidade, pois 
sua ação prescindiria de autorização legal. Mesmo que essas normas regulamentadoras tenham sido editadas pela própria administração pública, através do ministério do trabalho, tais normas não podem ser aplicadas aos servidores, simplesmente por não haver autorização legislativa para tanto.

Apesar dessa ressalva, cabe registrar que a lei autoriza a utilização da regulamentação do direito do trabalho no direito administrativo em apenas um dos temas de SST. Trata-se dos adicionais ocupacionais.

Essa autorização legislativa esta prevista no Decreto- Lei 1.873 de 27 de maio de 1981 que assim dispunha em seu artigo $1^{\circ}$ : "os adicionais de insalubridade e de periculosidade serão concedidos aos servidores públicos federais nas condições disciplinadas pela legislação trabalhista" (BRASIL, 1981, p.1).

Mesmo em sede de regulamento foi reiterada tal autorização através do decreto 97.458/89 nos seguintes termos "Art. 10 A caracterização e a classificação da insalubridade ou periculosidade para os servidores da administração federal direta, autárquica e fundacional serãofeitas nas condições disciplinadas na legislação trabalhista. (BRASIL, 1989, p.1)

Mais recentemente em 1991, já sob a égide da atual constituição (de 1988) houve nova autorização legislativa para aplicação da Regulamentação de adicionais ocupacionais do regime celetista aos servidores públicos. Essa autorização, que dessa vez foi realizada pelo congresso nacional, está disposta no artigo 12 da lei 8.270/91, nos seguintes termos "Os servidores civis da União, das autarquias e das fundações públicas federais perceberão adicionais de insalubridade e de periculosidade, nos termos das normas legais e regulamentares pertinentes aos trabalhadores em geral" (BRASIL, 1991)

Importante notar que mesmo diante dessa autorização expressa a lei estabeleceu uma diferença a ser aplicada entre os adicionais concedidos nesses em cada um dos regimes, conforme se depreende da análise do texto legislativo aplicável ao serviço público e ao regime celetista respectivamente. Primeiramente o artigo 12 da lei 8.270/91 que se aplica ao serviço público:

Art. 12. Os servidores civis da União, das autarquias e das fundações públicas federais perceberão adicionais de insalubridade e de periculosidade, nos termos das normas legais e regulamentares pertinentes aos trabalhadores em geral e calculados com base nos seguintes percentuais:

I - cinco, dez e vinte por cento, no caso de insalubridade nos graus mínimo, médio e máximo, respectivamente;

II - dez por cento, no de periculosidade.

$\S 1^{\circ} \mathrm{O}$ adicional de irradiação ionizante será concedido nos percentuais de cinco, dez e vinte por cento, conforme se dispuser em regulamento.

$\S 2^{\circ}$ A gratificação por trabalhos com Raios $X$ ou substâncias radioativas será calculada com base no percentual de dez por cento. 
$\S 4^{\circ} \mathrm{O}$ adicional de periculosidade percebido pelo exercício de atividades nucleares é mantido a título de vantagem pessoal, nominalmente identificada, e sujeita aos mesmos percentuais de revisão ou antecipação dos vencimentos. (BRASIL, 1991, p4)

Por fim as disposições sobre os adicionais ocupacionais aplicáveis aos trabalhadores em geral, estão previstas nos artigos 192 e 193 da CLT (Decreto Lei 5.453/43) nos seguintes termos:

Art.192 - O exercício de trabalho em condições insalubres, anteriormente dos limites de tolerância estabelecidos pelo Ministério do Trabalho, assegura a percepção de adicional respectivamente de $40 \%$ (quarenta por cento), $20 \%$ (vinte por cento) e $10 \%$ (dez por cento) do salário-mínimo da região, segundo se classifiquem nos graus máximo, médio e mínimo

Art. 193. São consideradas atividades ou operações perigosas, na forma da regulamentação aprovada pelo Ministério do Trabalho e Emprego, aquelas que, por sua natureza ou métodos de trabalho, impliquem risco acentuado em virtude de exposição permanente do trabalhador a:

I - inflamáveis, explosivos ou energia elétrica; (Incluído pela Lei no 12.740, de 2012)

II - roubos ou outras espécies de violência física nas atividades profissionais de segurança pessoal ou patrimonial. (Incluído pela Lei $n$ ㅇ 12.740, de 2012)

$\S 10$ - O trabalho em condições de periculosidade assegura ao empregado um adicional de $30 \%$ (trinta por cento) sobre o salário sem os acréscimos resultantes de gratificações, prêmios ou participações nos lucros da empresa

Diante da análise das disposições legais de ambos os regimes é possível fazer algumas observações. A primeira delas refere-se à diferença quanto aos percentuais dos adicionais que devem ser aplicados em cada um dos regimes. Embora haja autorização legal para se utilizar para os servidores públicos as normas legais e regulamentares aplicáveis aos trabalhadores me geral, o legislador reservou aos servidores adicionais ocupacionais com valores percentuais diferentes daqueles aplicáveis aos trabalhadores celetistas.

Outra diferença importante refere-se à base de cálculo desses adicionais. Enquanto no regime celetista os adicionais de insalubridade são calculados sobre o salário mínimo da região, e o adicional de periculosidade incide sobre o salário do empregado, no serviço público todos os adicionais serão calculados sobre o salário do servidor, e não sobre o salário mínimo regional.

Assim, tratando-se do adicional de insalubridade, é mais vantajosa para o trabalhador a lei aplicável ao serviço público, pois embora os percentuais sejam menores $(5 \% \%, 10 \%$ e $20 \%)$ conforme o tipo de exposição, esses percentuais incidem sobre o salário nominal do servidor.

Já no regime celetista, apesar de os percentuais serem mais elevados $(10 \%$, $20 \%$, e $40 \%$ ) estes são calculados sobre o salário mínimo da região, o que acarreta, na prática em um valor pecuniário menor a ser pagos aos trabalhadores celetistas em comparação com servidores públicos. 
Essa lógica se inverte, porém, no que diz respeito adicional de periculosidade. Nesse adicional a lei atribui vantagem maior para os trabalhadores celetista que fazem jus ao valor de $30 \%$ incidente sobre o salário do empregado a título de periculosidade. Os servidores expostos a agentes perigosos têm direito a um adicional de apenas $10 \%$.

Importante notar que os adicionais ocupacionais possuem, caráter transitório, e devem ser mantidos apenas enquanto durar a exposição. A neutralização ou eliminação do risco existente implica na elaboração de novo laudo de adicional ocupacional, no qual a nova situação quanto ao risco é registrada implicando na supressão do adicional que anteriormente se concedia. (BRASIL, 2013)

Esse laudo conforme os parágrafos 2 e 3 do artigo 10 da ON 6/2013:

§ 2o O laudo técnico deverá:

I - ser elaborado por servidor da esfera federal, estadual, distrital ou municipal ocupante do cargo público de médico com especialização em medicina do trabalho, ou de engenheiro ou de arquiteto com especialização em segurança do trabalho;

II - referir-se ao ambiente de trabalho e considerar a situação individual de trabalho do servidor;

III - preencher os requisitos do Anexo desta Orientação Normativa; e

IV - identificar: a) o local de exercício ou o tipo de trabalho realizado; b) o agente nocivo à saúde ou o identificador do risco; c) o grau de agressividade ao homem, especificando:

1. limite de tolerância conhecida, quanto ao tempo de exposição ao agente nocivo; $\mathrm{e}$

2. verificação do tempo de exposição do servidor aos agentes agressivos; d) classificação dos graus de insalubridade e de periculosidade, com os respectivos percentuais aplicáveis ao local ou atividade examinados; e e) as medidas corretivas necessárias para eliminar ou neutralizar o risco, ou proteger contra seus efeitos.

$\S 3$ O O laudo técnico não terá prazo de validade, devendo ser refeito sempre que houver alteração do ambiente ou dos processos de trabalho ou da legislação vigente. § 40 Compete ao profissional responsável pela emissão do laudo técnico caracterizar e justificar a condição ensejadora dos adicionais de insalubridade e de periculosidade. (BRASIL, 2013, p.2)

Superada a diferença entre os percentuais, nas demais disposições sobre adicionais ocupacionais a lei determina a aplicação aos servidores públicos das mesmas condições legais e regulamentares pertinentes aos trabalhadores em geral, sem distinção. Dessa forma, apenas no tocante aos adicionais ocupacionais autoriza a lei que se utilize no serviço publico a regulamentação sobre SST prevista para os trabalhadores em geral.

Dentre as trinta e cinco Normas Regulamentadoras atualmente em vigor a administração pública está expressamente autorizada por lei a utilizar apenas duas. A NR 15 (que trata das atividades e operações insalubres e a NR 16 (atividades e operações perigosas). Com a ressalva, todavia, quanto à diferenciação nos percentuais. As outras 33 (trinta e três) normas não receberam 
autorização para serem utilizadas no serviço público, e por esta razão em tese não deveriam ser utilizadas. Na prática, porém o que se vê é a utilização, ainda que indevida das normas regulamentadoras.

Importante notar que nem todas as normas regulamentadoras poderiam ser aplicadas ao serviço público. Isso porque, o serviço público implica na realização de atividades diferentes daquelas exercidas pela iniciativa privada. Diferente da iniciativa privada, cujas atividades visam de modo geral à obtenção do lucro, no serviço público o que se busca é alcançar o interesse público. Em razão dessa diferença algumas disposições das Normas Regulamentadoras, as quais foram elaboradas considerando as diferentes atividades econômicas, seriam inadequadas para as peculiaridades do serviço público.

\section{O subsistema integrado de atenção à saúde do servidor - SIASS}

Apesar da continuada omissão legislativa e regulamentar o governo federal, possivelmente em razão dos crescentes custos com o tema da SST no serviço publico tem feito algumas tentativas de implementar programas para trazer maior organização ao assunto no serviço público.

Exemplo dessas investidas do governo é a criação em 2009 de um órgão chamado - Subsistema Integrado de Atenção á Saúde do Servidor Federal - SIASS através do Decreto no 6.833 de 29/04/2009 (BRASIL, 2009).

O objetivo desse subsistema está definido no artigo $2^{\circ}$ do referido decreto:

Art. 2ㅇ O SIASS tem por objetivo coordenar e integrar ações e programas nas áreas de assistência à saúde, perícia oficial, promoção, prevenção e acompanhamento da saúde dos servidores da administração federal direta, autárquica e fundacional, de acordo com a política de atenção à saúde e segurança do trabalho do servidor público federal, estabelecida pelo Governo. (BRASIL, 2009, p.1)

O decreto de criação do SIASS não buscou disciplinar os temas relacionados à SST. O diploma buscou tão somente disciplinar e criar o chamado "subsistema" o qual funcionaria numa espécie de colaboração entre os órgãos públicos já existentes. O decreto que criou o SIASS revogou o decreto 5.961 editado três anos antes que havia criado outro órgão chamado Sistema Integrado de Saúde Ocupacional do Servidor Público Federal - SISOSP (BRASIL, 2006)

Essas duas iniciativas demonstram a uma maior preocupação do governo federal com a segurança e saúde de seus servidores. Os elevados custos com afastamentos, acidentes, doenças ocupacionais e seus desdobramentos possivelmente estão entre as principais razões dessa crescente preocupação.

Ações como o SISOSP e o SIASS representam importantes avanços no tema, porém a omissão legislativa e regulamentar sobre segurança e saúde do servidor público ainda é fator que prejudica o emprego de medidas mais satisfatórias de atenção à segurança e saúde do trabalhador. 


\section{MARCO TEÓRICO}

Para Delgado (2012) o direito do trabalho é um produto do capitalismo sua evolução esta ligada a evolução histórica desse sistema, retificando lhe distorções econômicas sociais e civilizando a importante relação de poder que sua dinâmica cria na sociedade civil. Dessa forma, com as importantes mudanças sociais trazidas pela revolução industrial, passa o trabalho a ser bem jurídico tutelado e disciplinado pelo direito.

\section{Os regimes de trabalho no Brasil}

São diversas as formas de manifestação do trabalho. Algumas delas nem mesmo importam ao direito laboral a exemplo do trabalho religioso, familiar, voluntário ou assistencial, etc. Há ainda os trabalhadores informais que respondem por uma parcela significativa da força de trabalho brasileira que da mesma forma em muitos casos não são atingidos pelo direito do trabalho (NASCIMENTO, 2011).

Além do direito do trabalho, outro ramo jurídico também comporta normas sobre o tema trabalho. Trata-se do direito Administrativo. De um lado estão os trabalhadores em geral (subordinados ao direito do trabalho) e de outros aqueles vinculados ao serviço publico (cujo regime é disciplinado pelo Direito Administrativo).

A primeira categoria agrega os trabalhadores regidos pela Consolidação das Leis Trabalhista - CLT (celetistas) e representa a maior parte dos trabalhadores com vínculos formais no Brasil. Para Farjalla (2013) o regime jurídico de direito privado (regido pelo direito do trabalho) é obrigatório na relação entre empregadores e empregados na iniciativa privada.

\section{O regime geral de trabalho no Brasil (regime CLT)}

Somente a partir do ano 1888 com a abolição do sistema escravista é que se pode falar em consolidação histórica do direito do trabalho no Brasil. Para Delgado (2012) a existência de trabalho livre (juridicamente livre) é pressuposto histórico material para o surgimento do trabalho subordinado, ou de relação empregatícia. Sem isso não há que se falar em ramo jurídico normatizador da relação de emprego. Assim, embora a lei Áurea não tenha qualquer caráter ou pretensão jus trabalhista ela representou o marco inicial do direito do trabalho no Brasil. Não significa que não havia relação de trabalho livre antes disso, significa que sua relevância não era tão grande em uma sociedade escravista.

O período entre 1888 e 1930 para Delgado (2012) representou um primeiro estágio para a questão do trabalho no Brasil. Esses anos são marcados por manifestações esparsas ou incipientes, pois as relações empregatícias se concentravam principalmente no setor agrícola cafeeiro e na emergente industrialização. Não havia ainda um movimento operário com grande capacidade de organização e pressão.

Os anos que seguiram a sanção da lei áurea, 1888, (BRASIL, 1888) e a proclamação da República, 1889, foram fortemente marcados pela influência da 
filosofia liberal, que defendia a não intervenção do estado na economia. Por essa razão o estado manteve-se alheio a proteção do trabalho.Nesse período houve uma intensa ocupação dos postos de trabalho por imigrantes vindos da Europa. $\mathrm{O}$ crescimento da presença de imigrantes no campo de trabalho brasileiro, para Nascimento (2011) criava as condições para que o trabalho passasse a ser regido por leis que garantissem a proteção do trabalhador. A insatisfação com as péssimas condições de trabalho, características desse período, acabaram se convertendo reivindicações e greves cada vez maiores e mais frequentes. 0 poder público, entretanto, em coerência com a filosofia liberal que pautava sua ação relutava em intervir nas relações trabalhistas, mesmo diante da intensa pressão que sofria.

A omissão do estado diante da visível injustiça social relacionada ao trabalho favoreceu o surgimento de diversos movimentos grevistas e a proliferação de ideias que propunham o combate dessa injustiça.

Os movimentos grevistas tornavam-se cada vez mais intensos, sobretudo após o ano de 1900. A despeito disso,as quatro décadas da republica velha foram marcadas por pouquíssimos avanços na questão trabalhista.

O início da Era Vargas em 1930 representaria uma profunda mudança de paradigma na questão trabalhista, cujos reflexos são sentidos em grande medida até os dias atuais. Nesse período houve uma grande expansão do direito do trabalho no Brasil. A par das conquistas anteriores (poucas, porém existentes) o momento político tornou-se propício para uma ampliação dos direitos laborais. Fortemente influenciada pelo modelo corporativista italiano a política trabalhista do governo Vargas passou a aceitar maior intervenção nas relações de trabalho passando o Estado a desempenhar papel central no tema.

Esse período, chamado por Delgado (2012) de fase de institucionalização do direito do trabalho firmou a estrutura jurídica e institucional de um novo modelo trabalhista. Nascimento (2011) ressalta que a despeito de se discutir as motivações que inspiraram Getulio Vargas se eram de dominação ou de elevação das classes trabalhadoras, o certo é que nesse período foi reestruturada a ordem jurídica trabalhista em nosso país, adquirindo fisionomia que em parte até hoje se mantém" (p. 99)

Entre as medidas tomadas por Vargas destaca-se a criação Ministério do Trabalho, Indústria e Comércio, no primeiro mês de seu governo através do decreto 19.433 de 26 de novembro de 1930 (BRASIL, 1930) outra medida de fundamental importância foi a instituição da Consolidação das Leis Trabalhistas CLT aprovadas pelo Decreto Lei 5.452 de $1^{\circ}$ de maio de 1943 (BRASIL, 1943). Apesar de diversas alterações ulteriores em seu texto original a CLT continua em vigor até os dias atuais, mesmo depois de ter passado pela edição de quatro constituições federais (1946, 1967, 1969 e 1988). Essa consolidação foi importante, pois antes dela, por muitos anos as leis trabalhistas cresceram de forma bastante desordenada.

Posteriormente a política econômica do período militar teve grande influência na ordem trabalhista. As leis trabalhistas passaram a ter um caráter econômico que as subordinavam às metas prioritárias como o combate a inflação. Surge a chamada política salarial do governo. Com a adoção dessa 
coletivas e da Justiça do Trabalho e a passava para o governo, que impunha uma padronização arbitrada pelo modelo oficial. (NASCIMENTO, 2011)

Nesse período há destaque para a implementação do Fundo de Garantia por Tempo de Serviço FGTS em 1966 ${ }^{1}$. O fundo que era uma compensação ao trabalhador pela perda do direito a estabilidade ${ }^{2}$ também se destinava ao financiamento do sistema habitacional (BRASIL, 1966). Há, ainda destaque para a edição da Lei n. 6.514 que modificou o Cap. V do Título II da CLT sobre Segurança e Medicina do Trabalho. Essa alteração legislativa foi seguida por uma ampla regulamentação trazida no âmbito do poder executivo pelo Ministério do Trabalho através das Normas Regulamentadoras sobre medicina e segurança do trabalho.

O advento da CF 1988 representou um importante marco para o direito do trabalho no Brasil. A chamada constituição cidadã trouxe em seu texto importantes direitos e garantias às pessoas. No capítulo II, são trazidos os chamados direitos sociais. Dentro desse capítulo, no artigo $7^{\circ}$ é dedicado aos direitos dos trabalhadores.

Entre as modificações expressivas trazidas pela CF 1988 estão:

A redução da jornada semanal de 48 para 44 horas; a generalização do regime do fundo de garantia com a consequente supressão da estabilidade decenal; a criação de uma indenização prevista para os casos de dispensa arbitrária; a elevação do adicional de horas extras para o mínimo de 50\%; o aumento em $1 / 3$ da remuneração das férias; a ampliação da licença da gestante para 120 dias; a criação da licença-paternidade, de 5 dias; a elevação da idade mínima de admissão no emprego para 14 anos; a descaracterização, como forma destinada a incentivar a iniciativa patronal, da natureza salarial da participação nos lucros; a instituição da figura do representante dos trabalhadores nas empresas com mais de 200 empregados; a reformulação da obrigatoriedade de creches e préescolas e a inclusão, agora em nível constitucional, de três estabilidades especiais, a do dirigente sindical, a do dirigente das Comissões Internas de Prevenção de Acidentes e a das empregadas gestantes. (NASCIMENTO, 2011, p. 106)

Em razão das inovações trazidas pela CF 1988 foram aprovadas diversas leis com o objetivo de regulamentar a Constituição Federal de 1988. Por essa razão formam aprovadas a Lei de Greve, Lei n. 7.783, de 28 de junho de 1989 (BRASIL, 1989a), a lei sobre política salarial, Lei n. 7.788, de 3 de julho de 1989 (BRASIL, 1989b) além da lei sobre o salário mínimo, Lei n. 7.789, de 3 julho de 1989 (BRASIL, 1989c). O Fundo de Garantia por Tempo de Serviço também foi objeto de atualização legal através Lei n. 8.036, de 11 de maio de 1990 (BRASIL, 1990).

As peculiaridades do período contemporâneo trouxeram importantes

\footnotetext{
${ }^{1}$ Instituído pela Lei n. ${ }^{\circ}$ 5.107, de 1966 (BRASIL, 1966).

${ }^{2}$ O artigo 492 da CLT dispõe: "o empregado que contar mais de 10 (dez) anos de serviço na mesma empresa não poderá ser despedido senão por motivo de falta grave ou circunstância de força maior, devidamente comprovadas". (BRASIL, 1943). O regime de estabilidade foi extinto sendo substituído pelo regime do FGTS. Segundo esse novo regime o trabalhador não padgquire estabilidade pelo decuros de tempo, mas diante de uma despedida arbitrária sem justa causa fará jus ao levantamento do valor depositado na conta em seu nome do FGTS, além de indenização no valor de $40 \%$ sobre o valor depositado pago pelo empregador que demitiu.
} 
transformações no direito do trabalho. A globalização, o avanço da tecnologia o desemprego etc. afetaram o direito do trabalho no Brasil, levando o estado a atenuar os efeitos negativos dessas transformações através de leis. Para Nascimento (2011) atualmente suas iderias aparentemente conflitantes caminham de forma paralela. O garantismo e a flexibilização.

\section{Os regimes jurídicos dos servidores públicos}

Ao lado do regime celetista que alberga a maior parte dos trabalhadores com vínculo de trabalho formal está outro regime que possui grande importância tanto pela quantidade de trabalhadores como pelo tipo de serviço prestado. Trata-se do regime dos servidores públicos. Enquanto o regime celetista baseia-se no direito do trabalho, o regime jurídico dos servidores públicos é disciplinado pelo direito administrativo. O regime do serviço público no Brasil é mais antigo do que o direito do trabalho, enquanto o direito do trabalho, começa a ser disciplinado apenas a partir da lei áurea em 1888, o regime dos servidores públicos já era objeto de deliberação na legislação há muito tempo.

O período monárquico, fase inicial da organização do estado brasileiro, de acordo com Araujo (2007) é marcado pela ausência de qualquer sistemática legal no que tange o estudo da função pública. Mesmo após a Carta Constitucional outorgada em 1824 o problema persistia. O documento previa poucos dispositivos relacionados aos servidores públicos. O artigo $15, \mathrm{XVI}$ do texto constitucional dispunha que cabia ao poder legislativo (Assembléia Geral composta pela Câmara dos Deputados e pelo Senado Federal), "criar ou suprimir empregos públicos e estabelecer-Ihes ordenados" (art. 15, XVI) (BRASIL, 1824).

O casuísmo foi o aspecto mais marcante dessa incipiente regulamentação dos direitos e deveres dos servidores públicos. As medidas tomadas não buscavam o alcance geral, mas se propunham a beneficiar interesses específicos de algumas categorias. Isso dificultava a relação entre o servidor e a administração sendo fonte de injustiças e discriminações. E foi essa a herança recebida pela república, que em seus primeiros anos pouco conseguiu avançar no sentido de uma regulamentação sistemática do serviço público (ARAÚJO, 2007).

A primeira constituição republicana, de 1891, apesar de trazer mais dispositivos sobre o tema dos servidores públicos do que sua antecessora (constituição imperial de 1824) não trouxe maiores avanços na sistematização do serviço público (BRASIL, 1891).

Nesse período havia nos serviços públicos a seguinte divisão: de um lado estava o grupo de servidores permanentes e estáveis chamados de funcionários públicos, ou empregados públicos, como também eram chamados. A esses se associavam cargos públicos, os quais eram organizados em carreiras e quadros. De outro lado havia o grupo dos chamados extranumerários, aos quais se associavam funções, e para os quais não havia cargos correspondentes (ARAUJO, 2007).

Araujo, (2007) ressalta que, apenas com o decreto legislativo 5.426 de 07 de janeiro de 1928 foram lançadas as bases para a sistematização desses dois grupos (BRASIL, 1928). 
Nos anos que seguiram vários foram os esforços, mal logrados, diga-se, de se estabelecer um aparato legislativo unitário para a função publica. A constituição de 1934 foi a primeira do Brasil a destinar uma parte específica aos funcionários públicos (Título VII, arts. 168 a 173). A constituição de 1934 acabou representando um impulso para a elaboração de um corpo sistematizado de normas regentes da função pública.

Durante a vigência da Constituição de 1937 (BRASIL, 1937), em pleno regime ditatorial, foi finalmente expedido o Decreto-Lei 1.713, de 28 de outubro de 1939 que passou a ser chamado de "Estatuto dos Funcionários Públicos Civis da União" (BRASIL, 1939).

Araujo (2007) destaca que texto original da CLT aprovado em 1943 pelo Decreto-Lei 5.452 excluiu de sua aplicação servidores públicos do Estado e das entidades paraestatais, servidores de autarquias administrativas cujos empregados estejam sujeitos a regime especial de trabalho. $O$ texto original da CLT proibiu ainda a associação sindical dos servidores do Estado e das instituições paraestatais (BRASIL, 1943).

A constituição de 1946 reservou um Título VII, que abarcava do artigo 184 ao 194, para tratar dos "Funcionários Públicos". Mas diferente das cartas de 1934 e 1937 silenciou sobre a obrigatoriedade do estabelecimento de um estatuto próprio aos Funcionários Públicos.

No dia 28 de outubro de 1952 foi promulgado o novo Estatuto dos Funcionários Públicos Civis da União através da Lei 1.711/1952 (BRASIL, 1952). O novo Código definia funcionário público como "pessoa legalmente investida em cargo público", cargo público por sua vez era definido como aquele "criado por lei, com denominação própria, em número certo e pago pelos cofres da União". O mesmo estatuto definia que a nomeação poderia se dar nas seguintes modalidades "em caráter vitalício", "de caráter efetivo", "em comissão" ou "interinamente" (ARAUJO, 2007)

Entre os anos 50 e 70 houve uma grande expansão do regime trabalhista entre os servidores públicos. Para Araujo (2007) a Lei 1.890, de 13 de junho 1953, representa o primeiro passo na introdução da legislação trabalhista comum para os integrantes da função pública.

Na mesma esteira a Lei 3.780 de 12 de julho de 1960 trouxe uma tentativa de sistematizar os servidores públicos em duas categorias (BRASIL, 1960). A primeira seria formada por funcionários públicos, tanto os ocupantes de cargos de provimento efetivo ou em comissão, com regimento pelo Estatuto de 1952 e legislação complementar. A outra categoria seria aquela formada por trabalhadores de obras e temporários, os quais se sujeitavam ao regime da CLT, bem como as outras leis a ele aplicáveis (ARAUJO, 2007).

Posteriormente, já sob a égide do regime militar, em 25 de fevereiro de 1967 foi promulgado o Decreto-Lei . $^{\circ} 200$ (BRASIL, 1967), que previa a possibilidade de contratação, pelo regime da CLT, de técnicos especializados para prestação de serviço à administração direta e às autarquias, e a contratação temporária de consultores técnicos e especialistas. Permitia ainda a contratação, sem vínculo empregatício, de trabalhadores eventuais (ARAUJO, 2007).

No mesmo sentido a constituição de 1967, que apesar de dedicar a seção ao tema dos servidores públicos, silencia em relação ao seu estatuto, determina a 
aplicação da legislação trabalhista aos servidores contratados para ocupar função de natureza técnica ou especializada, bem como aos servidores temporários (BRASIL, 1967).

Araujo (2007) ressalta que em 1974 a lei 6.185/74 (BRASIL, 1974) representou clara opção pelo regime trabalhista, previsto na $\mathrm{CLT}$, para o serviço público federal. Consagrou-se assim uma tendência, já amplamente difundida desde os anos de 1950.

Na década de oitenta, com o início dos trabalhos da assembléia nacional constituinte, o tema do regime dos servidores públicos veio novamente à tona. As décadas anteriores, marcadas por uma tendência de trazer o regime celetista para o serviço público, causaram uma intensa migração, de tal sorte, que na época em que se instaurou a constituinte a maior parte dos servidores públicos estava sob a égide desse regime:

A Constituição Federal de 1988 em seu texto original estabeleceu em seu artigo 39 que "A União, os Estados, o Distrito Federal e os Municípios instituirão, no âmbito de sua competência, regime jurídico único e planos de carreira para os servidores da administração pública direta, das autarquias e das fundações públicas" (BRASIL, 1988).

Seguindo a diretriz constitucional, a união editou em 11 de dezembro de 1990, portanto, pouco mais de dois anos após a promulgação da constituição, através da lei 8.112/90 o Regime Jurídico Único (RJU) dos servidores públicos da União (administração direta), das autarquias e fundações públicas federais (BRASIL, 1990). A união fez opção pelo regime típico de direito público (estatutário) para disciplinar o vinculo funcional de seus servidores. Dessa forma os empregos públicos existentes nas autarquias e fundações públicas federais foram transformados, de acordo com o artigo 243 , $\S 1^{\circ}$ da lei, na data de publicação da referida lei, em cargos públicos ${ }^{3}$ (ALEXANDRINO; PAULO, 2015).

Para Alexandrino e Paulo (2015) o legislador entendeu que o vínculo estatutário seria o mais adequado, pois os órgãos que compõe a administração pública federal (administração direta, autarquias e fundações) não se coadunam com organizações tipicamente empresariais. O poder de polícia além de outras prerrogativas públicas lastreadas no poder de império do estado, na maioria dos casos, é exercido por agentes públicos. E diferentemente do regime celetista, o regime estatutário é dotado de instrumentos que possibilitam atuação imparcial dos agentes públicos frente a indivíduos ou grupos que detenham influencia e poder político e econômico, o que, registre-se, nem sempre ocorre na prática.

\section{A segurança e Medicina do Trabalho}

Apesar de sua gravidade e de já ter sido identificado há muito tempo, o problema da ocorrência de acidentes e doenças relacionados ao trabalho não chamou muito a atenção de governantes durante milênios. Uma das principais razões para isso está no fato de que historicamente a mão de obra foi em sua maioria prestada por escravos, de tal sorte que "O mundo antigo teve na

Pả Art. 243, § 1으 Os empregos ocupados pelos servidores incluídos no regime instituído por esta Lei ficam transformados em cargos, na data de sua publicação (BRASIL, 1990). 
escravidão uma instituição universal" (FERRARI, 2011, p. 29), ou ainda por pessoas livres oriundas das camadas sociais economicamente menos favorecidas.

No século XVIII, com o advento da Revolução Industrial e consequente mudança na dinâmica do trabalho houve um notável aumento nos agravos a ele relacionados. Em razão disso, surgem na Inglaterra as primeiras normas de cunho trabalhista que visavam a redução dos riscos ocupacionais nos ambientes laborais (Lei de Saúde e Moral dos Aprendizes, que data de 1802). Na mesma linha, outras normas de conteúdo semelhante começaram a surgir nas demais nações que experimentavam o processo de industrialização (SANTOS, 2011).

Mais tarde o conjunto de normas de proteção ao trabalho, ou o direito do trabalho, ganha status constitucional passando a incorporar o texto da constituição de alguns países "as leis constitucionais pioneiras no direito do trabalho são a Constituição do México e a Constituição de Weimar, não se podendo omitir a Carta Del Lavoro" (NASCIMENTO, 2011, p. 401).

A tendência foi seguida e o tema da Saúde e Segurança no trabalho passou a ser objeto de tratamento constitucional em vários países "as Constituições da Bolívia (1967), Brasil (1934, 1937, 1946, 1967, 1969 e 1988), Costa Rica (1949), Equador (1947), México (1947) e Honduras (1957), além de outras, protegem o direito à segurança e higiene no trabalho." (NASCIMENTO, 2011, p. 849).

No Brasil o tema da segurança e da saúde no trabalho passou por um processo semelhante àquele vivenciado pelas economias centrais. Aqui, porém, os avanços foram mais tardios. Nos quatro séculos do Brasil colônia (entre os anos de 1500 a 1889) o trabalho braçal era exercido por escravos (tanto negro como índios) e por homens livres, porém pobres. Não havia grandes preocupações com a segurança e saúde desses trabalhadores, e as que haviam eram exclusivamente de cunho privadas (SANTOS, 2011).

Somente durante a República Velha (1889-1930) com o início do processo de industrialização do país as primeiras normas de proteção aos trabalhadores foram elaboradas pelo estado brasileiro. 0 momento de maior relevância foi a criação da Consolidação das Leis do Trabalho - CLT que foi instituída pelo Decreto-Lei n. no 5.452, de $1^{\circ}$ de maio de 1943 (BRASIL, 1943). Através do tempo diversas foram as alterações promovidas no texto original da CLT, inclusive com a promulgação da CF de 1988 (BRASIL, 1988), apesar disso, muitos dos institutos jurídicos esculpidos no texto original da CLT continuam em vigor.

A Lei no 6.514, de 22/12/77, alterou o Capítulo V, do Título II, da CLT, relativo à Segurança e Medicina do Trabalho. E, a Portaria no 3.214, de 08/06/78, aprovou as Normas Regulamentadoras de Segurança e Medicina do Trabalho (NR).

Essas Normas que embora tenham sido trazidas pela Portaria no 3.214/78 em vigor até hoje, têm sido regularmente alteradas ao longo do tempo por diversas Portarias (GONÇALVES; CRUZ, 2009). Além dessas alterações nas NR já existentes, houve o incremento de novas normas regulamentadoras e a revogação de uma das NR (NR-27) que estava entre as que originalmente foram publicadas.

A necessidade de se conferir efetividade às disposições legais da CLT sobre SST exigia uma regulamentação ao seu texto ante as peculiaridades do tema. "A complexidade e extensão da matéria levaram o Poder Executivo a discipliná-la 
por meio de 'normas regulamentadoras' (NR), aprovadas pela Portaria n. 3.214, de 8 de junho de 1978" (NASCIMENTO, 2011, p. 850).

A SST no âmbito do serviço público está disciplinada em diversos institutos legais. Diferentemente do regime dos trabalhadores em geral que concentra no texto da CLT as principais disposições sobre o tema, no serviço publico a SST é tratada em leis esparsas.

O estatuto do Servidor Público Federal, previsto na Lei 8.112/90, traz algumas disposições sobre a SST aplicável ao serviço público. Entretanto a questão dos adicionais e gratificações ocupacionais são o foco do tratamento legislativo. Outros temas relacionados à SST não são nem ao menos mencionados (BRASIL, 1990).

O mesmo acontece nos demais institutos legais que tratam da SST no serviço público. Ocupa-se tão somente de disciplinar a concessão dos adicionais e gratificações ocupacionais, como posteriormente demonstrado.

Além da lei 8.112/90 tratam do tema SST a lei 1.234/50 que confere direitos e vantagens a servidores que operam com Raios $X$ e substâncias radioativas (BRASIL, 1950) e a lei 8.270/91 que e seu artigo 12 amplia a disciplina legal sobre o tema dos adicionais e gratificações ocupacionais. Por fim há ainda o Decreto-Lei $\mathrm{n}$. 1.873/1981 que dispões sucintamente sobre a questão dos adicionais de insalubridade e periculosidade nos seguintes termos "Art. 1으 - Os adicionais de insalubridade e de periculosidade serão concedidos aos servidores públicos federais nas condições disciplinadas pela legislação trabalhista" (BRASIL, 1981).

As matérias disciplinadas nas leis anteriormente citadas estão regulamentadas nos seguintes instrumentos: Decreto no 81.384/1978, que dispõe sobre a concessão de gratificação por atividades com raios-x ou substância radioativas e outras vantagens, previstas na Lei ํo 1.234 /1950 (BRASIL, 1978), Decreto no 97.458/1989, que regulamenta a concessão dos Adicionais de Periculosidade e de insalubridade (BRASIL, 1989), Decreto no 877/1993, que regulamenta o adicional de irradiação ionizante (BRASIL, 1993) e na Orientação Normativa n. 6/2013 - SEGEP/MPOG, estabelece orientação sobre a concessão dos adicionais de insalubridade, periculosidade, irradiação ionizante e gratificação por trabalhos com raios-x ou substâncias radioativas (BRASIL, 2013).

Dessa forma, a legislação (tanto legal como regulamentar) sobre a Segurança e Saúde no Trabalho, no Serviço Público resume-se a disciplinar o tema dos adicionais e gratificações ocupacionais. Programas e medidas que visem promover melhorias através da eliminação ou diminuição de riscos nos ambientes laborais nem mesmo foram objeto de preocupação do legislador.

Esse panorama cria uma situação desfavorável ao servidor público, quando comparado aos trabalhadores em geral. Enquanto na iniciativa privada a matéria de Segurança e Saúde no Trabalho possui ampla regulamentação sobre os diversos aspectos do tema, no serviço público apenas se disciplina os adicionais e gratificações ocupacionais. Medidas que busquem a proteção à saúde e a segurança no laborar dos trabalhadores do setor público do público. Por essa razão é tão importante que o tema seja regulamentado no serviço público. 


\section{RESULTADOS DO ESTUDO}

Diante de todo o exposto evidencia-se a necessidade de criação de alternativas para a omissão legislativa e regulamentar sobre saúde e segurança no trabalho no regime jurídico único federal (estatutário) com vistas a garantir uma maior proteção a saúde e segurança no trabalho no setor público, além de garantir maior isonomia entre no tratamento dado ao tema no regime celetista e no regime estatutário. A despeito da natureza do vínculo de trabalho a que esteja submetido é direito constitucionalmente garantido ao trabalhador a "redução dos riscos inerentes ao trabalho, por meio de normas de saúde, higiene e segurança" (BRASIL, 1988, p.6).

Propostas de diretrizes ou alternativas que visem solucionar o problema da falta de regulamentação da SST no serviço público devem levar em consideração as peculiaridades do regime público de trabalho, que em comparação com o regime privado possui importantes diferenças, que fazem, inclusive, que esses dois regimes pertencem a ramos distintos do direito (direito administrativo e direito do trabalho, respectivamente).

O presente estudo apresenta três possíveis soluções para a omissão regulamentar no tema da SST no âmbito do serviço público, com base no estudo bibliográfico e documental realizado.

\section{Edição de Lei que autorize a utilização das Normas Regulamentadoras para o serviço público}

A primeira alternativa ou solução que se apresenta consiste na autorização através de lei federal para que sejam utilizadas também no serviço público as normas de Segurança e Medicina do Trabalho que são aplicáveis ao regime CLT. Essa solução é bastante simples na medida em que toda a estrutura normativa já utilizada no regime CLT poderá ser utilizada para os trabalhadores do serviço público.

De fato, o legislador já se utilizou, ainda que parcialmente, dessa opção quando autorizou a utilização no serviço público das normas regulamentadoras que versam sobre os adicionais ocupacionais. Conforme já exposto (no item 4.1.3, do capítulo 4 do presente trabalho) essa autorização está prevista tanto no decreto 97.458/89 (BRASIL, 1989) e na Lei 8.270/91 (BRASIL, 1991).

No caso dos adicionais ocupacionais a solução encontrada pelo legislador foi a de autorizar a utilização dos parâmetros gerias "nos termos das normas legais e regulamentares pertinentes aos trabalhadores em geral" (BRASIL, 1989), porém reservando-se no direito de modificar o percentual a ser aplicado no cálculo dos adicionais.

Solução semelhante poderia ser aplicada no caso das demais normas sobre SST. O legislador poderia autorizar a utilização ao serviço público, de forma genérica todas as disposições legais e normativas sobre SST, modificando apenas pontualmente alguns detalhes para o fim de uma melhor adequação ao regime do serviço público. Dessa forma, o arcabouço técnico previsto na normatização (legal e regulamentar) seria trazido também para o âmbito do serviço público, ressalvadas eventuais alterações que a seu critério quisesse o legislador deixar consignado. Dessa forma mediante autorização legal todas as normas 
regulamentadoras do MTE passariam a ser aplicáveis também ao serviço público (desde que cabíveis).

A vantagem dessa opção está em se aproveitar toda a estrutura normativa já existente no regime CLT. A experiência e conhecimento acumulados durantes as décadas de vigência das normas sobre SST no regime CLT seriam de enorme utilidade, sendo aproveitadas também pelos trabalhadores do serviço público.

A despeito dessa vantagem, há nessa opção importantes limitações. A principal está no fato de tais normas não se adequarem perfeitamente as peculiaridades do serviço público. $O$ estado em regra não desenvolve atividade econômica. Segundo o texto do artigo 173 da CF de 1988 a exploração pelo estado desse tipo de atividade somente se admite excepcionalmente: "Ressalvados os casos previstos nesta Constituição, a exploração direta de atividade econômica pelo Estado só será permitida quando necessária aos imperativos da segurança nacional ou a relevante interesse coletivo, conforme definidos em lei (BRASIL, 1988).

Para Bulos (2009) a CF/88 ao adotar o sistema capitalista relega a iniciativa privada o desenvolvimento de atividades de cunho econômico.

Logo, o dispositivo delimitou a esfera da iniciativa econômica pública
e privada, atendendo a reivindicações privatistas. Ao fazê-lo, traçou
um novo perfil estatal no campo da economia, restringindo a
participação do Estado, o qual, para explorar diretamente uma
atividade econômica, deverá resguardar a própria soberania
nacional (imperativos de segurança nacional) ou os interesses
maiores da sociedade (relevante interesse coletivo) (BULOS, 2009, p.
30)

Dessa forma, quando comparada com as atividades desenvolvidas pela iniciativa privada, de cunho predominantemente econômicas, as atividades desenvolvidas pelo estado (os serviços públicos, ou as atividades típicas de estado) possuem importantes diferenças.

A regulamentação sobre SST no regime CLT, portanto, presta-se a normatizar atividades econômicas desenvolvidas no âmbito da iniciativa privada. Sua aplicação no serviço público, pode em muitas vezes ser inadequada.

A título de exemplo cita-se o caso da caracterização do adicional de insalubridade pela exposição ocupacional à agentes químicos. Os anexos 11, 12 e 13 da NR 15 ao disciplinar os adicionais de insalubridade estabelecem níveis de concentração de agentes químicos que apenas seriam aferidos no ambiente industrial.

No âmbito do serviço público, quando, por exemplo se pretende avaliar a exposição ocupacional de docentes e técnicos em laboratórios universitários, verifica-se que os anexos anteriormente citados se mostram inadequados. Isso por que esses textos normativos, ao partirem de hipóteses pensadas para a indústria, muitas vezes impossibilitam a caracterização do adicional de insalubridade para esses trabalhadores, pois os ensaios realizados nesses laboratórios utilizam os agentes químicos em menor escala do que na indústria.

Negligencia-se o fato de que no laboratório embora a quantidade de cada agente químico seja menor, em razão dos fins didáticos a que se destinam, a variedade de produtos utilizados nos diversos ensaios realizados é bem maior. 
Além disso, não é possível viabilizar o mesmo tipo de proteção aos trabalhadores em razão das necessidades peculiares da atividade didática.

Dessa forma, há de se registrar a limitação existente em se adotar a normatização do regime CLT ao serviço público.

\section{Elaboração de uma Lei geral de segurança e saúde do servidor público}

Outra possível solução refere-se à elaboração de uma lei geral sobre SST no âmbito do serviço público, que contemplasse além de disposições normativas legais a previsão de uma regulamentação própria. Tal solução seria mais trabalhosa já que demandaria estudos e trabalhos para se chegar a elaboração de uma lei que previsse os diferentes aspectos da SST no serviço público. Além disso, demandariam ainda a necessidade de uma ampla regulamentação do conteúdo das disposições legais.

Em razão disso, essa solução implica necessariamente em morosidade. Estudos, e avanços políticos, no âmbito executivo e legislativo demandariam grande tempo e sobretudo vontade política, o que costuma ser volátil nas transições naturais no poder que são características do regime democrático.

Apesar de mais trabalhosa, tal solução seria positiva na medida em que traria uma normatização (legal e regulamentar) específica para o serviço público, contemplando as peculiaridades inerentes as atividades ou serviços prestados pelo estado.

Isso por que as atividades prestadas pelo estado, sobretudo pelos entes de direito público que compõe sua estrutura (administração direita e autarquias e fundações públicas na administração indireta), possuem características bastante peculiares quando comparadas com as atividades econômicas que caracterizam a iniciativa privada.

Edição de Lei que exija dos órgãos da administração pública que disciplinem o tema no âmbito de seus órgãos

A terceira solução apresentada seria a regulamentação no âmbito de cada órgão através da edição de uma lei que exigisse que tal disciplina ocorresse de maneira descentralizada dando a cada órgão discricionariedade na elaboração de sua própria normatização. Essa solução, apesar de não ter caráter de disciplina geral poderia ser positiva no sentido de que cada órgão teria liberdade para estabelecer sua própria disciplina utilizando até mesmo avanços já alcançados.

O problema seria a falta de padronização que acabaria por desfavorecer a avanços uniformes, além de dificultar a implementação de medidas de ordem geral que favoreçam o avanço no tema da SST globalmente.

Portanto, são três as alternativas propostas para dirimir o problema da omissão legislativa verificada. Cada uma delas traz consigo vantagens e desvantagens. As três implicam na elaboração de lei, pois conforme já explanado, não se pode negligenciar o princípio da legalidade a que está submetida a administração pública. 


\section{CONSIDERAÇÕES FINAIS}

O trabalho tem papel fundamental na vida das pessoas ocupando parte significativa do tempo de suas vidas. Muitas vezes o trabalho é exercido em condições que acarretam em riscos para a saúde e a integridade física dos trabalhadores.Esses riscos atingem trabalhadores de todos os regimes de trabalho. Sejam empregados regidos pelo regime CLT ou servidores estatutários, todos estão submetidos à ocorrência dos agravos relacionados ao trabalho.

Por isso é fundamental que a regulamentação sobre SST tenha abrangência geral abarcando inclusive os trabalhadores do setor público. Não é razoável que parcela significativa dos trabalhadores brasileiros fique excluída da proteção legal sobre SST que já é aplicada com bastante êxito na iniciativa privada. Programas como o PPRA, o PCMSO e medidas como a CIPA são fundamentais e devem fazer parte das iniciativas obrigatórias de proteção ao trabalhador do serviço público.

O presente trabalho apresenta alternativas viáveis para sanar o grave problema da falta de regulamentação da matéria de SST no âmbito do serviço publico federal. Explora a formação histórica dos dois principais regimes de trabalho existentes no Brasil com o intuito de localizar a Segurança e a Medicina do trabalho no contexto de cada um deles. Discute os assuntos mais relevantes da regulamentação existente sobre o tema nos dois regimes. Identifica o tratamento dado ao tema da segurança e saúde no trabalho no regime celetista e no regime estatuário do serviço público federal; comparar os dois regimes no tocante ao tema de SST. Por fim propõe alternativas para superar possíveis omissões legislativas e regulamentares da legislação sobre segurança e saúde no trabalho aplicável ao serviço público com intuito de resguardar princípios gerais de proteção ao trabalhador bem como uma maior isonomia com os trabalhadores celetistas.

As alternativas propostas invariavelmente passam pela elaboração de lei. 0 trabalho não pretende culminar na elaboração legislativa, pois sabidamente esse é um processo bastante complexo. $\mathrm{O}$ que se busca é tão somente discutir o tema no âmbito teórico e, identificar e propor alternativas para sanar o problema respeitando as diversas faces da questão.

Diante disso, três são as alternativas apresentadas como solução para a referida omissão legislativa 1) a edição de Lei que autorize a utilização das Normas Regulamentadoras para o Serviço Público; 2) a elaboração de uma Lei geral de segurança e saúde do servidor público; e 3) a edição de Lei que exija dos órgãos da administração pública que disciplinem o tema no âmbito de seus órgãos.

As vantagens e desvantagens de cada uma dessas alternativas são expostas para viabilizar a discussão sobre qual delas seria a mais adequada para equacionar o problema aduzido.

Apesar disso, não se deve ignorar o fato de que as possibilidades de um trabalho teórico como esse são bastante limitadas para atingir um resultado prático. Ao final a solução para o problema dependerá da conjugação de diversos fatores econômicos, sociais e políticos que sejam capazes de despertar a vontade política, único elemento efetivamente capaz de sanar o problema exposto. 
como resultado a apresentação de alternativas para superar a omissão legislativa e regulamentar sobre saúde e segurança no trabalho no regime jurídico único federal, o que é fundamental para garantir uma maior isonomia de tratamento entre os servidores públicos e os trabalhadores do regime celetista no tocante proteção de sua saúde e segurança no trabalho.

Ademais os objetivos específicos também foram atingidos na medida em que foi identificou-se o tratamento dado ao tema da segurança e saúde no trabalho no regime celetista e no regime estatuário do serviço público federal. Comparouse o tema da SST nos dois regimes. Foram identificadas as principais diferenças existentes no trato normativo (leis e regulamentos) sobre saúde e segurança do trabalho de um regime em relação ao outro, ressaltando os problemas, incoerências e contradições que delas são emanados. E ainda foram propostas alternativas para solução dos problemas encontrados. 


\title{
Safety and health at work in the CLT regime and in the statutory regime: an approach of governmental planning comparing the theme in the two regimes
}

\begin{abstract}
Occupational safety and health OSH is a subject of great relevance, mainly due to the high financial, social and health costs of workers related to the hazards arising from the risks that exist in work activities. Since the Industrial Revolution and in Brazil since the end of slavery, the issue has gradually become more important and drawing the attention of public authorities. In Brazil, SST is widely approached and disciplined in labor legislation through the provisions of the Consolidation of Labor Laws (CLT) and the Regulatory Norms issued by the Ministry of Labor, as well as other related legal instruments. However, in the scope of the public service the reality is quite different. Although the public sector has several activities that imply risks to the health and physical integrity of its workers, the SST is marked by the legislative omission in this sector. While in the CLT the legal and regulatory discipline of the subject is quite broad, in the public service, the discipline of the subject is to deal with occupational additions, leaving aside important programs and measures used in the scheme. The objective of this study is to propose alternatives to remedy the legislative and regulatory omission on OSH in the single federal (statutory) legal regime.
\end{abstract}

KEY WORDS: Safety. Health. Workplace. CLT. Public. 


\section{REFERÊNCIAS}

ALEXANDRINO, Marcelo; PAULO, Vicente. Direito Administrativo Descomplicado. São Paulo: Editora Método. 2015.

ARAÚJO, Florivaldo Dutra de. Os Regimes Jurídicos dos Servidores Públicos no Brasil E Suas Vicissitudes Históricas. Revista da Faculdade de Direito da UFMG. Belo Horizonte, no 50, p. 143-169, jan. - jul., 2007

BRASIL. Constituição da República dos Estados Unidos do Brasil. Rio de Janeiro, 16 de jul. de 1934b. Disponível em http://www.planalto.gov.br/ccivil_03/Constituicao/Constituicao34.htm. Acesso em: 07 de março de 2016.

BRASIL. Constituição da República Federativa do Brasil de 1967. Rio de Janeiro, 24 de janeiro de 1967. Disponível em:

http://www.planalto.gov.br/ccivil_03/Constituicao/Constituicao67.html. Acesso em: 23 de fevereiro de 2016.

BRASIL. Constituição da República Federativa do Brasil de 1988. Brasília, 5 out. 1988. Disponível em http://www.planalto.gov.br/ccivil_03/decretolei/Del5452.htm. Acesso em: 23 de fevereiro de 2016.

BRASIL. Constituição dos Estados Unidos do Brasil. Rio de Janeiro, 10 de novembro de 1937. Disponível em:http://www.planalto.gov.br/ccivil_03/Constituicao/Constituicao37.htm. Acesso em: 23 de fevereiro de 2016.

BRASIL. Constituição Política do Império do Brazil. Rio de Janeiro, 22 de abr. de 1824. Disponível em http://www.planalto.gov.br/ccivil_03/Constituicao/Constituicao24.htm. Acesso em: 26 de fevereiro de 2016.

BRASIL. Decreto 5.426 de 7 de Janeiro de 1928. Rio de Janeiro. Altera disposições do Codigo de Contabilidade da União e dá outras providencias7 de jan. de 1928. Disponível em:

http://www2.camara.leg.br/legin/fed/decret/1920-1929/decreto-5426-7-janeiro2016. 
BRASIL. Decreto 5.961, de 13 de novembro de 2006. Institui o Subsistema Integrado de Atenção à Saúde do Servidor Público Federal - SIASS e o Comitê Gestor de Atenção à Saúde do Servidor. - SISOSP. Disponível em: http://www.planalto.gov.br/ccivil_03/_ato2007-2010/2009/decreto/d6833.htm Acesso em: 12 de novembro de 2016.

BRASIL. Decreto 6.833 de 29 de abril de 2009. Institui o Sistema Integrado de Saúde Ocupacional do Servidor Público Federal - SISOSP.

http://www.planalto.gov.br/ccivil_03/_ato2004-

2006/2006/decreto/D5961impressao.htm Acesso em: 12 de novembro de 2016.

BRASIL. Decreto 97.458 de 11 de janeiro de 1989. Regulamenta a concessão dos Adicionais de Periculosidade e de Insalubridade. Disponível em: http://www.planalto.gov.br/ccivil_03/leis/L8270.htm. Acesso em: 12 de novembro de 2016.

BRASIL. Decreto 97.458 de 11 de janeiro de 1989. Regulamenta a concessão dos Adicionais de Periculosidade e de Insalubridade. Disponível em: http://www.planalto.gov.br/ccivil_03/leis/L8270.htm. Acesso em: 12 de novembro de 2016.

BRASIL. Decreto n. 19.433, de 26 de novembro de 1930. Cria uma Secretaria de Estado com a denominação de Ministério do Trabalho, Indústria. Rio de Janeiro, 26 de novembro de 1930. Disponível em: http://www2.camara.leg.br/legin/fed/decret/1930-1939/decreto-19433-26novembro-1930-517354-publicacaooriginal-1-pe.html.Acesso em: 27 maio 2016.

BRASIL. Decreto-Lei n.o 1.711, de 28 de outubro de 1952. Dispõe sobre o Estatuto dos Funcionários Públicos Civis da União.Rio de Janeiro, 28 de outubro de 1952. Disponível em: http://www.planalto.gov.br/ccivil_03/leis/19501969/L1711impressao.htmAcesso em: 27 de maio 2016.

BRASIL. Decreto-Lei n.o 1.713 de 28 outubro de 1939a. Dispõe sobre o Estatuto dos Funcionários Públicos Civis da União.Rio de Janeiro, 28 de outubro de 1939. Disponível em: http://www.planalto.gov.br/ccivil_03/decreto-lei/19371946/Del1713.htm. Acesso em: 27 de maio 2016.

BRASIL. Decreto-Lei n.o 1.8733, de 27 de maio de 1981. Dispõe sobre a concessão de adicionais de Insalubridade e de periculosidade aos servidores públicos federais, e dá outras providências. Brasília, 27 de maio de 1981. https://www.planalto.gov.br/ccivil_03/decreto-lei/1965-1988/Del1873.htm. Acesso em: 22 de fevereiro de 2016. concessão de adicionais de Insalubridade e de periculosidade aos servidores públicos federais, e dá outras providências. Brasília, 27 de maio de 1981. 
https://www.planalto.gov.br/ccivil_03/decreto-lei/1965-1988/Del1873.htm. Acesso em: 22 de fevereiro de 2016.

BRASIL. Decreto-Lei $\mathbf{n}^{\circ} \mathbf{5 . 4 5 2}$, de $\mathbf{1}^{\circ}$ de maio de 1943 . Aprova a Consolidação das Leis do Trabalho. Brasília, $1^{\circ}$ maio 1943. Disponível em http://www.planalto.gov.br/ccivil_03/decreto-lei/Del5452.htm. Acesso em: 22 de fevereiro de 2016.

BRASIL. Lei $n$. . 3.353 , de 13 de maio de 1888. Declara extinta a escravidão no Brasil. Rio de Janeiro, 13 de maio de 1888. Disponível em: http://www.planalto.gov.br/ccivil_03/leis/LIM/LIM3353.htm Acesso em: 27 maio 2016.

BRASIL. Lei n. 3.780, de 12 de julho de 1960. Dispõe sôbre a Classificação de Cargos do Serviço Civil do Poder Executivo, estabelece os vencimentos correspondentes e dá outras providências. Rio de Janeiro, 12 de julho de 1960. Disponível em: http://www.planalto.gov.br/Ccivil_03/LEIS/19501969/L3780.htm. Acesso em: 27 de maio 2016.

BRASIL. Lei n.o 5.107, de 13 de setembro de 1966. Cria o Fundo de Garantia do Tempo de Serviço, e dá outras providências.Rio de Janeiro, de 13 de setembro de 1966. Disponível em:

http://www.planalto.gov.br/ccivil_03/leis/L5107impressao.htm. Acesso em: 27 maio 2016.

BRASIL. Lei $n$. 0 6.185, de 11 de dezembro de 1974. Dispõe sobre os servidores públicos civis da Administração Federal direta e autárquica, segundo a natureza jurídica do vínculo empregatício, e dá outras providências. Rio de Janeiro, 11 de dezembro de 1974. Disponível em: http://www.planalto.gov.br/CCivil_03/LEIS/1970-1979/L6185.htm. Acesso em: 27 de maio 2016.

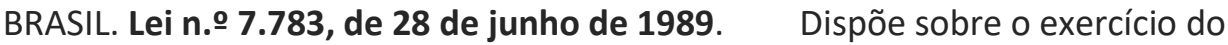
direito de greve, define as atividades essenciais, regula o atendimento das necessidades inadiáveis da comunidade, e dá outras providências. Brasília, 28 de junho de 1989. Disponível em:http://www.planalto.gov.br/ccivil_03/leis/L7783.htm

BRASIL. Lei n.o 7.789, de 3 julho de 1989 . Dispõe sobre o salário mínimo. Brasília,3 de julho de 1989 . Disponível em: http://www.planalto.gov.br/ccivil 03/leis/L7789.htm

BRASIL. Lei n.o 8.036, de 11 de maio de 1990. Dispõe sobre o Fundo de Garantia do Tempo de Serviço, e dá outras providências. Brasília, 11 de maio de 1990. Disponível em: http://www.planalto.gov.br/ccivil 03/leis/L8036consol.htm 
BRASIL. Lei n. 8.270, de 17 de dezembro de 1991 . Dispõe sobre reajuste da remuneração dos servidores públicos, corrige e reestrutura tabelas de vencimentos, e dá outras providências. Disponível em:

http://www.planalto.gov.br/ccivil_03/leis/L8270.htm. Acesso em: 12 de novembro de 2016.

BRASIL. Lei no 8.112, de 11 de dezembro de 1990. Dispõe sobre o regime jurídico dos servidores públicos civis da União, das autarquias e das fundações públicas federais. Brasília, 12 dez.1990. Disponível em: http://www.planalto.gov.br/ccivil 03/LEIS/L8112cons.htm Acesso em: 05 jan. 2016.

BRASIL. Orientação Normativa № 6, de 18 de Março de 2013 da Secretaria De Gestão Pública do Ministério do Planejamento, Orçamento e Gestão. Estabelece orientação sobre a concessão dos adicionais de insalubridade, periculosidade, irradiação ionizante e gratificação por trabalhos com raios-x ou substâncias radioativas, e dá outras providências. Disponível em: file:///C:/Users/Pc/Downloads/ORIENTA\%C3\%87\%C3\%830\%20NORMATIVA\%206 \%20-\%202013\%20(6).pdf. Acesso em: 12 de novembro de 2016.

BRASIL.Lei n. 7.788, de 3 de julho de 1989. Dispõe sobre a política salarial e dá outras providências. Brasília,3 de julho de 1989. Disponível em: http://www.planalto.gov.br/ccivil_03/leis/L7788impressao.htm. Acesso em: 12 de novembro de 2016.

BULOS, UadiLammêgo. Constituição Federal anotada. 9. ed. São Paulo: Saraiva, 2009, p. 1262.

DELGADO, Maurício Godinho. Curso de direito do trabalho. 11. ed. - São Paulo: LTr, 2012.

FARJALLA, Victor. O Servidor Público. Reflexões sobre seu Regime Jurídico. Revista de Direito da Procuradoria Geral. Rio de Janeiro (67), 2013.

GONÇALVES, Ligia Bianchi; CRUZ, Vania MassambaniCorazzada.Segurança e medicina do trabalho. São Paulo:Cenofisco Editora, 2009.

MELLO, Celso Antonio Bandeira de. Curso de direito administrativo. São Paulo: Malheiros, 2010.

NASCIMENTO, Amauri Mascaro. Curso de direito do trabalho : história e teoria 
OIT - Organização Mundial do Trabalho, 2016. Disponível em:

http://www.oitbrasil.org.br/content/hist\%C3\%B3ria. Acesso em 23 de fevereiro de 2016.

PASTORE, José. 0 custo dos acidentes e doenças do trabalho no Brasil. Disponível em:http://www.josepastore.com.br/artigos/rt/rt 320.htm. Acesso em: 03 de maio de 2016.

REVISTA PROTEÇÃO. Anuário 2015 . Disponível em:

http://www.protecao.com.br/conteudo/anuario_brasileiro_de_p_r_o_t_e_c_a_o /anuario_2015/J9yJA5_JayAJa. Acesso em 06 de maio de 2016.

SANTOS, Adolfo Roberto Moreira. Saúde e segurança no trabalho no Brasil: aspectos institucionais, sistemas de informação e indicadores. Brasília: Ipea, 2011. Disponível em: http://www.sintespar.com.br/LivroSaudeWeb.pdf. Acesso em 28 de janeiro de 2016.

Recebido: 17 jul. 2017

Aprovado: 19 nov. 2017

DOI: $10.3895 /$ rbpd.v7n1.5679

Como citar: ALMEIDA, J. C.; LIMA, I. A. A segurança e saúde no trabalho no regime CLT e no regime estatutário: uma abordagem no planejamento governamental comparando o tema nos dois regimes. R. bras.

Planej. Desenv.,Curitiba, v. 7, n. 1, p. 2-28, jan./abr. 2018.Disponível em:

$<$ https://periodicos.utfpr.edu.br/rbpd>. Acesso em: XXX.

Correspondência:

Isaura Alberton de Lima

Av. Sete de Setembro, 3165 - Rebouças CEP 80230-901 - Curitiba - PR - Brasil

Direito autoral: Este artigo está licenciado sob os termos da Licença CreativeCommons-Atribuição 4.0

Internacional.

\section{(c) (1)}

